University of Wollongong

Research Online

Faculty of Engineering and Information

Faculty of Engineering and Information

Sciences - Papers: Part A

Sciences

$1-1-2015$

Axial compressive behaviour of GFRP tube reinforced concrete columns

Muhammad N. S Hadi

University of Wollongong, mhadi@uow.edu.au

Weiqiang Wang

University of Wollongong,ww674@uowmail.edu.au

M Neaz Sheikh

University of Wollongong, msheikh@uow.edu.au

Follow this and additional works at: https://ro.uow.edu.au/eispapers

Part of the Engineering Commons, and the Science and Technology Studies Commons

Research Online is the open access institutional repository for the University of Wollongong. For further information contact the UOW Library: research-pubs@uow.edu.au 


\title{
Axial compressive behaviour of GFRP tube reinforced concrete columns
}

\author{
Abstract \\ This paper presents an innovative reinforcing scheme for concrete columns using glass fibre reinforced \\ polymer (GFRP) tubes. GFRP tubes (solid and perforated) have been placed into concrete columns to \\ provide reinforcement in both longitudinal and transverse directions. In this study, 14 columns with 150 \\ $\mathrm{mm}$ diameter and $300 \mathrm{~mm}$ height have been cast and tested under axial compression. The columns have \\ been divided into seven groups; each group contains two columns. The first group of columns are the \\ reference columns without any reinforcement. The other six groups of columns are reinforced with solid \\ and perforated (axially and diagonally) GFRP tubes. The test results show that GFRP tubes are effective in \\ improving the strength and the ductility capacity of FRP (fibre reinforced polymer) Tube Reinforced \\ Concrete (FTRC) columns. Also, perforated GFRP tubes have been found effective in integrating concrete \\ core with concrete cover. However, axially perforated FTRC columns have been found most effective \\ considering the strength and the ductility capacity of the concrete columns. In addition to the \\ experimental investigations, numerical simulations have been carried out to assess the influence of tube \\ perforations on the behaviour of FTRC columns. The simulation results show that reduction in the hole \\ diameter, rather than increase in the vertical hole spacing, is the most effective in increasing the strength \\ and the ductility capacity of FTRC columns.

\section{Disciplines} \\ Engineering | Science and Technology Studies \\ Publication Details \\ Hadi, M. N. S., Wang, W. \& Sheikh, M. Neaz. (2015). Axial compressive behaviour of GFRP tube reinforced \\ concrete columns. Construction and Building Materials, 81 198-207.
}


* Corresponding author

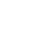

\section{Correspondence:}

Muhammad N. S. Hadi

\title{
Axial compressive behaviour of GFRP tube reinforced concrete columns
}

\author{
Muhammad N. S. Hadi *, Weiqiang Wang and M. Neaz Sheikh
}

School of Civil, Mining and Environmental Engineering, University of Wollongong,

NSW 2522, Australia

School of Civil, Mining \& Environmental Engineering

University of Wollongong, Australia

E-mail: mhadi@uow.edu.au

Telephone: + 61242214762

Facsimiles: + 61242213238 


\section{Axial compressive behaviour of GFRP tube reinforced concrete columns}

Abstract: This paper presents an innovative reinforcing scheme for concrete columns using glass fibre reinforced polymer (GFRP) tubes. GFRP tubes (solid and perforated) have been placed into concrete columns to provide reinforcement in both longitudinal and transverse directions. In this study, 14 columns with $150 \mathrm{~mm}$ diameter and $300 \mathrm{~mm}$ height have been cast and tested under axial compression. The columns have been divided into seven groups; each group contains two columns. The first group of columns are the reference columns without any reinforcement. The other six groups of columns are reinforced with solid and perforated (axially and diagonally) GFRP tubes. The test results show that GFRP tubes are effective in improving the strength and the ductility capacity of FRP (fibre reinforced polymer) Tube Reinforced Concrete (FTRC) columns. Also, perforated GFRP tubes have been found effective in integrating concrete core with concrete cover. However, axially perforated FTRC columns have been found most effective considering the strength and the ductility capacity of the concrete columns. In addition to the experimental investigations, numerical simulations have been carried out to assess the influence of tube perforations on the behaviour of FTRC columns. The simulation results show that reduction in the hole diameter, rather than increase in the vertical hole spacing, is the most effective in increasing the strength and the ductility capacity of FTRC columns.

Keywords: GFRP tubes; Internal reinforcement; Perforated tubes; Axial compression; Numerical simulation. 
55 GFRP tube is used as reinforcement for FRP Tube Reinforced Concrete (FTRC) columns.

56 Perforated GFRP tubes integrate concrete core with concrete cover.

57 GFRP tube improves the strength and the ductility capacity of FTRC columns.

58 Influence of tube perforation on the behaviour of FTRC columns is numerically assessed.

59

60

61

62

63

64

65

66

67

68

69

70

71

72

73 


\section{Introduction}

75

76

77

Steel bars have been traditionally used as reinforcement in the construction of reinforced concrete (RC) structures. However, corrosion of steel bars has been the major cause of deterioration of RC structures, especially for structures subjected to harsh environment, which compromises the serviceability of the structure. The cost of repair and restoration for the deteriorated structures due to corrosion of reinforcement can be significantly high. Many methods have been applied to protect reinforcement from corrosion including the use of galvanized or stainless steel bars, epoxy coating and cathodic protection [1-4]. However, none of these methods have provided a drastic solution to this problem [5].

Over the last three decades, a significant number of studies have been carried out on the use of advanced composite materials, such as fibre reinforced polymer (FRP), in civil engineering structures. Recent studies showed that FRP composites (FRP bars) can be successfully used in RC beams in flexure [6, 7]. However, the use of FRP bars as longitudinal reinforcement has not been considered a suitable option for RC compression members. The main reasons for not using the FRP bars in building columns and bridge piers are: (a) the strength and stiffness of FRP bars in compression are less than that in tension [8,9]; (b) a tensile strength reduction of more than $40 \%$ can occur for transverse FRP bars with bends compared to the tensile strength of straight bars due to fibre bending and stress concentration [10]; and (c) the longitudinal FRP bars are vulnerable to local bucking [11]. Also, the use of FRP bars in columns has not yet been covered in ACI 440.1R-06 [12].

Recent research investigation showed that FRP jackets can enhance both strength and ductility capacity of RC columns by providing confining effect to the concrete core under concentric and eccentric axial loadings [13-16]. The FRP jacket was used mostly for retrofitting of existing columns and to some extent for new construction of in-situ RC columns. Recently, concrete-filled FRP tubes 
(CFFTs) have gained significant research attentions. In CFFTs, the FRP tube acts as stay-in-place formwork and provides lateral confinement to concrete core. At the same time, the concrete core prevents the FRP tube from local buckling. Existing studies have demonstrated the ability of CFFTs to develop considerable strength, stiffness and ductility capacity, making FRP tubes attractive alternatives of steel bars [17-19]. Despite many advantages, CFFTs present some design challenges: (a) the susceptibility of FRP tube to be damaged in fire or under impact loading limits the application of CFFTs in critical infrastructure [20,21], (b) linear elastic behaviour of FRP materials until rupture causes the RC columns confined with FRP tubes fail in a brittle manner without prior warning; and (c) the interfacial debonding between FRP tube and concrete may occur due to insufficient bonding strength especially in column under flexural loading [19].

In this study, a new reinforcing scheme, named FRP Tube Reinforced Concrete (FTRC) columns is proposed. The FRP tube is placed into the concrete to provide reinforcement in both longitudinal and transverse directions. In this scheme, the FRP tube is also protected by the concrete cover. In addition to solid GFRP tubes, perforated GFRP tubes are also used in order to integrate the concrete core and concrete cover effectively. Compared to CFFTs, the fire performance and impact resistance of the FTRC columns can be significantly improved because the concrete cover protects the GFRP tube. The spalling of concrete cover can be used as a suitable indication of the imminent failure. Also, mechanical interlockings can be developed between the perforated GFRP tube and concrete (Fig. 1), forming a higher interfacial shear strength [22]. In order to have an in-depth understanding of the axial compressive behaviour of the proposed FTRC columns, an experimental programme was conducted in the High Bay Civil Engineering Laboratory at the University of Wollongong. The axial load-axial deformation behaviour of FTRC columns has been investigated. The strength, ductility capacity and failure modes of the FTRC columns have been critically studied. Finally, numerical simulations have been carried out to investigate the influence of perforation on the axial compressive behaviour of FTRC columns. 


\section{Experimental program}

126

127

\subsection{Materials and column specimens}

Glass fibre reinforced polymer (GFRP) tubes manufactured by Wagners Australia were chosen as the reinforcement material. The solid GFRP tubes (ST) were $260 \mathrm{~mm}$ long and $6 \mathrm{~mm}$ thick with $77 \mathrm{~mm}$ internal diameter. In addition to solid GFRP tubes, perforated tubes were selected as well. The purpose of using perforated tubes is mainly to integrate the concrete core with concrete cover, which may prevent the concrete cover from premature spalling. $25 \mathrm{~mm}$ diameter circular holes were drilled to create perforations into the GFRP tubes. Two different perforation patterns (axial and diagonal) were studied. Axially perforated GFRP tubes have been designated as APT and diagonally perforated GFRP tubes have been specified as DPT in this study. Four rows of holes were drilled in each tube. The rows were symmetrically distributed along the tube circumference. The clear vertical spacing between holes was $40 \mathrm{~mm}$. 16 holes were drilled in APT and 14 holes were drilled in DPT. Moreover, in order to prevent the GFRP tubes from premature rupture and to improve the hoop tensile strength, two layers of Carbon Fibre Reinforced Polymer (CFRP) sheet were wrapped onto the tubes (Fig. 2). The laterally wrapped GFRP tubes were labelled ST-LW, APT-LW, and DPT-LW, in which "LW" means the tube was laterally wrapped with CFRP sheet. Fig. 2 shows different GFRP tubes used in this study.

A total of 14 circular columns were cast and tested under axial compression. The columns were 150 $\mathrm{mm}$ in diameter and $300 \mathrm{~mm}$ in height. Concrete clear cover was $30 \mathrm{~mm}$ on the sides and $20 \mathrm{~mm}$ at the top and bottom of the columns. The columns were divided into seven groups. Each group contained two identical columns. The columns were made of normal strength concrete with a design compressive strength of $32 \mathrm{MPa}$. The maximum size of the coarse aggregate for concrete was $10 \mathrm{~mm}$. Details of the columns are shown in Fig. 3. 
151 Table 1 lists the columns tested in this study. Group REF columns were used as reference columns 152 which contain no reinforcement. Group ST columns were reinforced with solid GFRP tube. Group 153 APT and DPT columns were reinforced with APT and DPT, respectively. For Group ST-LW, APT154 LW, and DPT-LW columns, laterally wrapped ST, APT, and DPT, respectively, were used as 155 reinforcement.

2.2.1. Tube perforation and CFRP attachment

For the perforated GFRP tubes, hole locations were marked before drilling. A drill press machine with a $25 \mathrm{~mm}$ circular drill bit was used to perforate the tubes. Gloves and a mask were worn to get protected from harmful fibres during the perforation operation. A water spray bottle was used to wash away any waste material. After perforation, GFRP tubes labelled ST-LW, APT-LW, and DPT-LW were laterally wrapped with two layers of CFRP sheets. A mixture of epoxy resin and hardener at 5:1 ratio was used. Before the application of the first layer of CFRP, the adhesive was spread onto the surface of the tube. After the first layer, the adhesive was spread onto the first layer of CFRP and the second layer was continuously bonded. $70 \mathrm{~mm}$ overlap was maintained. All wrapped GFRP tubes were left to dry for seven days.

\subsubsection{Casting of columns}

Plastic moulds were used to cast the concrete columns. The moulds were made of PVC pipes with 150 mm inner diameter and $300 \mathrm{~mm}$ height. GFRP tubes were placed into the mould first. In order to ensure a $20 \mathrm{~mm}$ concrete cover at the top and bottom, three tiny holes were drilled into the timber base as well as at the bottom of GFRP tubes. The holes were $10 \mathrm{~mm}$ in depth. Afterwards, three 40 
mm long thin steel wires were inserted into the holes to support the GFRP tubes and to maintain 20 mm concrete cover. The steel wires were removed from the concrete columns after curing of concrete. To ensure $30 \mathrm{~mm}$ cover at sides, four thin steel wires were aligned symmetrically around the top end of GFRP tube. The steel wires were removed after two thirds of the concrete had been cast. Each mould was stabilized vertically by three galvanized steel straps and two hose clips. Fig. 4 shows the layout of GFRP tubes in the moulds.

After GFRP tube was placed into the mould, concrete was mixed and cast according to AS 1012.91999 [23] and AS 1012.8.1-2000 [24]. A wet hessian was placed over the columns to prevent moisture loss. All the columns were watered during weekdays until the test date. To prevent premature failure, the top and the bottom of the columns were strengthened by two layers of CFRP sheets. $70 \mathrm{~mm}$ overlapping was applied at the top and the bottom of the columns. Fig. 5 shows the GFRP tube reinforced concrete columns.

\subsection{Preliminary tests}

Concrete cylinders with $100 \mathrm{~mm}$ diameter and $200 \mathrm{~mm}$ height were tested for compressive strength at 7 and 28 days. The average compressive strengths at 7 and 28 days were $26 \mathrm{MPa}$ and $35 \mathrm{MPa}$, respectively. The properties of CFRP sheet were determined by FRP coupon tests accordance to ASTM D7565 [25]. The average width of the coupons was $28.50 \mathrm{~mm}$ and the average maximum tensile force was $1200 \mathrm{~N} / \mathrm{mm}$. The average ultimate tensile strain was calculated as $0.0172 \mathrm{~mm} / \mathrm{mm}$.

The properties of GFRP tubes were determined by tube axial compression test. Six GFRP tubes, with one tube for each type, were tested under axial compression. Fig. 6 shows the axial load-axial deformation diagram of GFRP tubes under axial compression. Table 2 lists the ultimate load and the corresponding axial deformation of GFRP tubes. For solid GFRP tube, the average ultimate axial 
compressive strength was $400 \mathrm{MPa}$ and the corresponding axial strain was $0.014 \mathrm{~mm} / \mathrm{mm}$. The axial elastic modulus was $33 \mathrm{GPa}$, which was close to the value provided by the manufacturer (35.4 GPa). It is evident that perforations can significantly reduce the axial elastic modulus and load carrying capacity of GFRP tubes. Even though less perforation was created for DPT, the ultimate load and the corresponding axial deformation were less than those of APT, which indicates that APT performs better than DPT under axial compression. Moreover, the wrapping of CFRP sheet did not significantly improve the ultimate load and the corresponding deformation of the tubes. Fig. 7 shows the failure modes of different GFRP tubes after axial compression test. ST and ST-LW failed due to stress concentration at the tube end, while perforated GFRP tubes failed due to the rupture around holes.

\subsection{Instrumentation and test procedure}

Strain gauges were longitudinally and transversely attached onto the GFRP tubes to investigate the actual strain at representative locations. Two pairs of strain gauges were used for each column in Groups ST, APT and DPT. Each pair contains two strain gauges attached at the mid-height of the GFRP tube aligned in the longitudinal and transverse directions. Two representative locations were selected for perforated tubes. The first location (Point A) was in the middle of two neighboring holes, and the second location (Point B) was in the intact part of GFRP tubes, as shown in Fig. 8. For each column in Groups ST-LW, APT-LW, and DPT-LW, two strain gauges were attached onto the CFRP sheet to capture the tensile strains of CFRP sheet in the mid-height of GFRP tubes.

The Denison $5000 \mathrm{kN}$ testing machine in the High Bay laboratory at University of Wollongong was used for testing all the columns. Before testing, all columns were capped at the top end with high strength plaster to ensure uniform load application. The columns were placed vertically on the steel plate. Adequate care was taken to ensure that the columns were placed at the centre of the testing machine. Axial deformations were measured using two Linear Variable Differential Transformers (LVDTs), which were mounted at the corners between the loading plate and supporting steel plate. 
The deformation readings from the two LVDTs were then averaged to obtain representative result. The load and deformation data were recorded using an electronic data-logger connected to a computer for every two seconds. The displacement controlled tests were carried out at a rate of $0.5 \mathrm{~mm} / \mathrm{min}$. All columns were tested until failure.

\section{Experimental results and discussion}

\subsection{Failure modes}

Although there was an increase in the ultimate strength of a few columns, all reinforced columns failed in a brittle manner with rupture of GFRP tubes. Typical failure modes of the columns are shown in Fig. 9. The failure modes depend largely on the configuration of GFRP tubes. Group ST and Group ST-LW columns failed due to the transverse rupture and in-plane shear at the mid-height of the GFRP tubes. For columns in Group APT and Group APT-LW, longitudinal rupture was observed around the holes. Group DPT columns failed due to longitudinal rupture in the middle of three neighbouring holes, while Group DPT-LW columns failed due to the rupture around the holes where CFRP was not attached.

\subsection{Axial load-axial deformation behaviour}

Fig. 10 shows the axial load-axial deformation behaviour of Groups REF, ST, APT and DPT columns. It can be seen that all columns showed similar behaviour before yielding. Afterwards, columns reinforced with GFRP tubes showed decrease in the strength with increase in the deformation. This behaviour is attributed to the spalling of concrete cover. It is noted that the concrete cover was $30 \mathrm{~mm}$ at the sides and hence significant decrease in the strength of the columns was expected. Afterwards, the strength of the columns was increased with the increase in the axial deformation because of the confining effect provided by GFRP tubes. Eventually, all the columns failed due to the rupture of the GFRP tubes, accompanied by very loud noises. It is evident from Fig. 10 that several fluctuations 
occurred before total failure. These fluctuations suggest that even after the rupture of GFRP tubes, columns can still sustain considerable amount of load because of the contribution of concrete. Fig. 11 shows the axial load-axial deformation behaviour of Groups REF, ST-LW, APT-LW, and DPT-LW columns. Groups ST-LW, APT-LW, and DPT-LW columns show similar behaviour to those of Groups ST, APT, and DPT columns, respectively. It is noted that for Column ST-LW-2, the deformation at ultimate load was $8.26 \mathrm{~mm}$, which was even lower than that of Group ST columns. However, from the tube compression test, it was predicted that ST-LW columns should have a higher ultimate load and the corresponding axial deformation than those of Group ST columns. This inconsistency may be attributed to operating error during the test. Therefore, the test result of Column ST-LW-2 has not been considered for further analyses.

Table 3 summarizes the test results of all columns. The yield load, the ultimate load as well as the corresponding axial deformations have been presented. In this study, the ultimate load is defined as the load at the rupture of FRP tube. The ductility of the columns [26, 27] has been calculated as:

$$
\mu=\frac{\delta_{u}}{\delta_{y}}
$$

where $\mu$ is the ductility of the column, $\delta_{u}$ is the deformation at the ultimate load, and $\delta_{y}$ is the deformation at the yield load.

It can be seen from Table 3 that Groups ST and ST-LW columns show significant increase in both the load carrying capacity and the ductility capacity. Group ST-LW columns achieved the highest load carrying capacity and ductility capacity. For perforated GFRP tube reinforced concrete columns in Groups APT, APT-LW, DPT, and DPT-LW, the ultimate load and ductility capacity increased while the increase was less than those of Groups ST and ST-LW columns. There might be two reasons for such behaviour. First, compared to $77 \mathrm{~mm}$ diameter concrete core, the spalling of $30 \mathrm{~mm}$ concrete 
cover would obviously result in a significant strength loss. Second, the perforation produced a strength reduction for the GFRP tubes, as explained above. For Groups APT and APT-LW columns, the ultimate load and the ductility capacity were higher than those of Groups DPT and DPT-LW columns, respectively. The lowest ultimate loads and ductility capacities were observed for Group DPT-LW columns. The results indicate that the axially perforated GFRP tube (APT) performs better than the diagonally perforated GFRP tube (DPT) in reinforcing the columns.

It is also important to note that the axial deformation at ultimate load for Group APT-LW columns is lower than that of Group APT columns. This can be explained by the fact that the wrapping of CFRP sheet onto the intact part of APT tubes might have resulted in the development of more minor cracks around the holes. Hence, APT-LW tube experienced a premature rupture around the holes than APT tube. Similarly, for Group DPT-LW columns, though a majority of the tube was wrapped with CFRP sheet, there were still areas around the holes that were not protected by CFRP sheet, and the rupture occurred around the unwrapped areas. Therefore, the attachment of CFRP sheet was insignificant in improving the load carrying capacity and the ductility capacity of Group DPT-LW columns. Nevertheless, the comparison between Group ST columns and Group ST-LW columns shows that the attachment of CFRP sheet onto solid GFRP tube could improve the load carrying capacity and the ductility capacity of Group ST-LW columns, because the CFRP sheet could potentially confine the lateral expansion of solid GFRP tube.

Table 4 shows the confinement effects of GFRP tubes. The $P_{c}$ is the ultimate load of the columns, $P_{c 0}$ is the unconfined concrete strength times the area of the concrete core, $P_{f}$ is the ultimate load of the GFRP tubes. The $\left(P_{c 0}+P_{f}\right)$ represents the ultimate load of the columns without confinement. It can be seen that the load carrying capacity of FTRC columns exceed the load carrying capacity of the two individual materials. The GFRP tubes significantly improved the load carrying capacity of the 
columns. Even though the perforation adversely reduced the axial elastic modulus and strength of GFRP tubes, the confinement effect did not show significant difference.

\subsection{Axial deformation-volumetric strain behaviour}

In order to understand the dilatation behaviour of concrete core, the axial deformation-volumetric strain response was calculated from the recorded strain gauge data. The volumetric strain $\varepsilon_{v}$ is determined from [28]:

$$
\varepsilon_{v}=\varepsilon_{\mathrm{A}}+2 \varepsilon_{H}
$$

where $\varepsilon_{A}$ and $\varepsilon_{H}$ are the axial strain and hoop strain, respectively. In this study, the axial compressive strains are considered negative and the hoop tensile strains are considered positive. Hence, a positive $\varepsilon_{v}$ means dilation and a negative $\varepsilon_{v}$ means volume contraction.

It has been reported that the volumetric change of FRP confined concrete depends significantly on the amount of FRP [29]. If the concrete was confined by a relatively less amount of FRP, the concrete may exhibit volumetric dilation at failure. However, if the concrete was confined by a sufficient amount of FRP, the concrete may not show dilation at all. Fig. 12 shows the axial displacementvolumetric strain response for Groups ST, APT and DPT columns. Group ST columns exhibited a continuous contraction, which indicates the efficiency of confinement provided by GFRP tube. For Group APT columns, the strain gauges measurement at the intact part (Point B) as well as around the hole area (Point A) were used to calculate the volumetric strain. The locations of Point A and Point B are shown in Fig. 8. It can be seen that the volumetric strain at the intact part (Point B) of APT exhibited a slight contraction initially followed by a slight dilation. Finally the column failed with a large volumetric contraction at point B. On the contrary, the volumetric strain around hole area (Point A) experienced a continuously increasing volume dilation until failure after slight volume contraction 

experienced a continuous volumetric contraction until the final failure, while the volumetric strain around the hole area (Point A) was subjected to contraction first and continuous dilation afterwards. The difference in volumetric strains between different parts of perforated GFRP tube indicates that the intact part is more effective in confining the concrete.

\section{Numerical simulations}

Finite element simulations of FTRC columns under axial compression were carried out to investigate the effect of hole diameter and hole spacing on the strength and the ductility capacity of columns. The numerical simulation considers the complexities of the concrete nonlinearity, the orthotropic properties of the GFRP tubes, and the confinement effect of GFRP tubes. The simulation model has been validated with the experimental result presented in Section 3 of this paper.

\subsection{Modelling method}

The nonlinear concrete model in [30] was used to simulate the concrete behaviour. In the concrete model, the stress-strain relationship of the concrete in compression exhibits nearly linear elastic response up to about $30 \%$ of the concrete compressive strength, which is followed by plastic behaviour until the compressive strength of concrete is reached. Beyond the compressive strength, the concrete stress-strain relationship exhibits strain softening until crushing. Fig. 13 (a) shows the idealized uniaxial stress-strain curve for the concrete and Fig. 13 (b) shows the biaxial failure surface of the concrete. The stress-strain relationship for concrete in tension is assumed to follow a linear ascending branch with a slope that is equal to the concrete modulus of elasticity $\left(E_{c}\right)$ until maximum tensile stress $\left(\sigma_{t}\right)$ is reached. In this study, the smeared crack model, in which it is assumed that a plane of failure is developed perpendicular to the corresponding principal stress direction, is used. The 
normal and the shear stiffness across the plane of failure are reduced and plane stress conditions are assumed to exist at the plane of tensile failure. Poisson's ratio $(v)$ is considered as 0.2 . The tangent modulus of concrete at zero strain $\left(E_{0}\right)$ is considered as $26 \mathrm{GPa}$. The unconfined concrete compressive strength is considered as $35 \mathrm{MPa}$ with a corresponding strain of 0.002 .

The orthotropic material model was used to simulate GFRP tubes. Orthotropic material properties used in the simulation are shown in Table 5. It can be seen from Table 5 that the ultimate tensile strength, ultimate compressive strength, and elastic modulus in the longitudinal direction are much higher than the ultimate tensile strength, ultimate compressive strength and elastic modulus in transverse direction, respectively. The higher values in the longitudinal direction can be attributed to the manufacturing method of the GFRP tubes used in this study. During the pultrusion process, a vast proportion of the glass fibres were aligned along the longitudinal direction of the GFRP tubes.

3-D solid elements were used to represent the concrete and FRP tubes. Each element contains 10 nodes, and each node has three degrees of freedom. In order to improve the convergence, the modelling techniques adopted are: (a) application of compatible element mode, (b) selection of higher numerical integration order, (c) adoption of the displacement convergence criterion, and (d) application of automatic time stepping (ATS) method. The birth/death element was used to simulate the spalling of concrete cover. After the concrete cover element was set to death, the concrete cover was assumed to be spalled off and was not considered for subsequent calculations. Displacement was applied on the top end of the column, and the loading speed was set to $0.005 \mathrm{~mm} / \mathrm{s}$. Fig. 14 shows the finite element model of ST column. 
373

374

376

377

The modelling method presented in Section 4.1 was validated with experimental results. Since it has been proven that APT columns exhibit higher strength and ductility capacity than DPT columns, APT columns were modelled. ST columns were modelled as well.

Figs. 15 (a, b) show the comparison of simulation result and experimental result of axial strain-axial load response of ST column and APT column, respectively. It is noted that the axial strain was obtained at the mid-height of GFRP tube. It can be seen that both the test and simulation results show very similar behaviour under axial compressive loading. The simulation results underestimate the load carrying capacity of the column especially beyond the cover spalling, which indicates that the strength enhancement of concrete core may not have been fully reflected. Nonetheless, the finite element model predicts the ultimate load carrying capacity and the ultimate strain, which are the main parameters of investigation in this study, with a reasonable accuracy.

\subsection{Effect of hole diameter}

The effect of hole diameter on the strength and the ductility capacity of columns was investigated using the developed finite element model. Four hole diameters ( $0 \mathrm{~mm}, 15 \mathrm{~mm}, 21 \mathrm{~mm}, 28 \mathrm{~mm}$ ) were considered. The vertical hole spacing for all perforated GFRP tubes was $40 \mathrm{~mm}$. Other simulation parameters were kept constant. Fig. 16 shows the axial load-axial strain diagram of columns reinforce by GFRP tubes with different hole diameters. It is evident that the reduction of hole diameter increases the load carrying capacity of concrete columns, although axial strains at ultimate loads are very similar. Fig. 17 (a) represents GFRP tube with $15 \mathrm{~mm}$ hole diameter and Fig. 17 (b) represents GFRP tube with $28 \mathrm{~mm}$ hole diameter. It can be seen from Fig. 17 that by reducing hole diameter, more intact part of tube can be obtained, thus a higher load carrying capacity can be achieved. Also, by reducing hole diameter, more concrete core can be effectively confined with GFRP tube, which can result in a higher strength improvement for concrete core. Therefore, it can be assumed that the strength of FTRC columns is highly dependent on the hole diameters of the perforated GFRP tubes. It 
is also evident that $25 \mathrm{~mm}$ hole diameter is very large for GFRP tube with $89 \mathrm{~mm}$ outer diameter to maintain the load carrying capacity of the columns.

\subsection{Effect of vertical hole spacing}

401

The effect of vertical hole spacing was investigated by simulating GFRP tube reinforced concrete columns with three different vertical hole spacings $(25 \mathrm{~mm}, 50 \mathrm{~mm}, 75 \mathrm{~mm}$ ). The hole diameter for all perforated GFRP tubes was $15 \mathrm{~mm}$. Other simulation parameters were kept constant. The axial strain- axial load responses of columns are shown in Fig. 18. It can be seen that the load carrying capacity increases with the increase in hole spacing, although axial strains at ultimate loads are very similar. By increasing the hole spacing, more concrete core can be effectively confined, which results in a higher strength improvement of concrete core. In addition, larger hole spacing means less perforation, which can also enable columns to sustain higher load (Fig. 19). Therefore, it can be assumed that the strength of FTRC columns also depends on the vertical hole spacing of the perforated GFRP tubes. However, the influence of vertical hole spacing is less than the influence of hole diameter on the load carrying capacity of FTRC columns.

412 Based on the simulation result, higher strength of FTRC columns can be obtained by reducing the hole diameter instead of increasing the vertical hole spacing of perforated GFRP tubes. Similarly, the vertical hole spacing can be reduced without causing significant strength degradation of FTRC columns where increased perforation area is required.

416 Even though perforation may influence the performance of FTRC columns under axial compression,

417 it is essential in the design of FTRC columns. When FTRC columns are exposed to high temperature, 418 the concrete cover spalling may occur for columns reinforced with intact FRP tubes because the 419 bonding between concrete cover and FRP tube may decrease significantly due to the high pressure 420 induced by water vapour inside concrete [31]. On the other hand, in presence of holes, even though 421 the bonding between concrete cover and FRP tube may decrease under high temperature, the mechanical interlocking between concrete core and cover may remain highly effective in preventing 
423 the cover from spalling. Moreover, the presence of holes on the FRP tube increases the bonding

424 strength between concrete core and FRP tube [22].

\section{5. Conclusions}

427 Experimental investigations and numerical finite element simulations were carried out to study the 428 axial compressive behaviour of FRP Tube (solid and perforated) Reinforced Concrete (FTRC) 429 columns. Based on the experimental and simulation results, the following conclusions can be drawn:

430 FTRC columns are effective in increasing the strength and the ductility capacity of concrete columns. 431 Concrete columns reinforced with laterally wrapped solid GFRP tubes (ST-LW) achieved the highest 432 strength and the ductility capacity than the other groups of columns in this study.

433 The use of perforated GRRP tubes is mainly to integrate the concrete core and concrete cover, which 434 is essential to protect the concrete cover from premature spalling (e.g., due to fire or impact loading). 435 However, the perforation may result in the loss of strength and the ductility capacity of FTRC 436 columns.

437 The numerical simulation results show that reduction of the hole diameter or increase of vertical hole 438 spacing can be effective in increasing the strength and the ductility capacity of FTRC columns. 439 However, as the reduction of hole diameter is more effective, it is suggested that hole diameter be 440 reduced rather than the vertical hole spacing be increased for the design of effective FTRC columns.

441 FTRC columns can be utilized in building and other applications where strict fire performance and 442 impact load resistance are necessary and where traditional RC columns are located in aggressive 443 environment which may lead to corrosion of steel reinforcement. 
446 Acknowledgments

447 The authors gratefully acknowledge the contributions of Messrs Alan Grant, Ritchie Mclean and

448 Fernando Escribano for their help in carrying out the experiments. The authors thank Mr. Eric Lume

449 for his advice for the casting of RC columnns. The authors also thank Wagners Australia for

450 providing GFRP tubes. The second author acknowledges the China Scholarship Council and the

451 University of Wollongong for supporting his $\mathrm{PhD}$ scholarship.

452

453

454

455

456

457

458

459

460

461

462

463

464

465

466

467

468

469 


\section{References}

471 [1] Bellezze T, Malavolta M, Quaranta A, Ruffini N, Roventi G. Corrosion behaviour in concrete of three differently galvanized steel bars. Cement and Concrete Composites 2006; 28(3):246-255.

[2] Castro H, Rodriguez C, Belzunce FJ, Canteli AF. Mechanical properties and corrosion behaviour of stainless steel reinforcing bars. Journal of Materials Processing Technology 2003; 143(1):134-137.

[3] Manning DG. Corrosion performance of epoxy-coated reinforcing steel: North American experience. Construction and Building Materials 1996; 10(5):349-365.

[4] Paul MC, John PB. Cathodic protection of steel in concrete. London, E \& FN Spon; 2003.

[5] Xi Y, Abu-Hejleh N, Asiz A, and Suwito A. Performance evaluation of various corrosion protection systems of bridges in Colorado. Report No. CDOT-DTD-R-2004-1, Colorado Department of Transportation; 2004.

[6] Benmokrane B, Chaallal O, Masmoudi R. Flexural response of concrete beams reinforced with FRP reinforcing bars. ACI Structural Journal 1996; 93(1):46-55.

[7] Yost JR, Gross SP, Dinehart DW. Shear strength of normal strength concrete beams reinforced with deformed GFRP bars. Journal of Composites for Construction 2001; 5(4):268-275.

[8] Wu WP. Thermomechanical properties of fibre reinforced plastic (FRP) bars. PhD dissertation, 486 West Virginia University, Morgantown, WV; 1990: 292pp.

[9] Mallick PK. Fibre reinforced composites, materials, manufacturing, and design. New York, Marcell Dekker; 1988.

[10] Nanni A, Rizkalla S, Bakis C, Conrad JO, Abdelrahman A. Characterization of GFRP ribbed rod 1998:11-16. 
492 [11] De Luca A, Matta F, Nanni A. Behaviour of full-scale glass fibre-reinforced polymer bars 493 reinforced concrete columns under axial load. ACI Structural Journal 2010;107(5):589-596.

494 [12] ACI 440.1R. Guide for the design and construction of structural concrete reinforced with FRP bars. USA: American Concrete Institute, Farmington Hills; 2002.

[13] Lam L, Teng JG. Design-oriented stress-strain model for FRP-confined concrete. Construction and Building Materials 2003; 17(6-7): 471-489.

[14] Ozbakkaloglu T, Lim JC, Vincent T. FRP-confined concrete in circular sections: review and assessment of stress-strain models. Engineering Structures 2013; 49: 1068-1088.

[15] Hadi MNS. Behaviour of FRP strengthened concrete columns under eccentric compression 501 loading. Composite Structures 2007; 77(1): 92-96.

[16] Hadi MNS. The behaviour of FRP wrapped HSC columns under different eccentric loads. Composite Structures 2007; 78(4): 560-566.

[17] Fam A, Rizkalla S. Behaviour of axially loaded concrete-filled circular fibre-reinforced polymer tubes. ACI Structural Journal 2001; 98(3): 280-289.

[18] Fam A, Schnerch D, Rizkalla S. Rectangular filament wound GFRP tubes filled with concrete 507 under flexural and axial loading: Experimental investigation. Journal of Composites for Construction 508 2005; 9(1):25-33.

509

[19] Fam A, Rizkalla S. Flexural behaviour of concrete-filled fibre reinforced polymer circular tubes. Journal of Composites for Construction 2002; 6(2):123-132.

511 [20] Ji G, Li G, Li X, Pang S, Jones R. Experimental study of FRP tube encased concrete cylinders 512 exposed to fire. Composite Structures 2008; 85(2):149-154.

513 [21] Abrate S. Impact on laminated composites. Applied Mechanics Reviews 1991, 44:155-190. 
514 [22] Ji G, Ouyang Z, Li G. Experimental investigation into the interfacial shear strength of AGS-FRP 515 tube confined concrete pile. Engineering Structures 2009;31(10):2309-16.

516 [23] AS 1012.9-1999. Methods of testing concrete. Standards Australia Limited, NSW; 1999.

517 [24] AS 1012. 8.1-2000. Methods of testing concrete: Method of making and curing concrete 518 Compression and indirect tensile test specimens. Standards Australia Limited, NSW; 2000.

519 [25] ASTM D7565/D7565M-10. Standard test method for determining tensile properties of fibre 520 reinforced polymer matrix composites used for strengthening of civil structures. United States: ASTM 521 International; 2010.

522 [26] Cui C, Sheikh, S.A. Experimental study of normal- and high-strength concrete confined with 523 fibre-reinforced polymers. Journal of Composites for Construction 2010; 14(5):553-561.

524 [27] Sheikh MN, Tsang HH, McCarthy TJ, Lam NTK. Yield curvature for seismic design of circular 525 reinforced concrete columns. Magazine of Concrete Research 2010; 62 (10): 741-748.

526 [28] Samaan, M, Mirmiran, A, Shahawy, M. Modeling of concrete confined by fibre composites. Journal of Structural Engineering, 1998; 124(9):1025-1031.

528

[29] Teng JG, Lam L. Behaviour and modelling of FRP-confined concrete. Journal of Structural 529 Engineering, 2004, 130(11):1713-1723.

530

[30] ADINA. Automatic dynamic incremental nonlinear analysis. In. 8.3 ed. Watertown, MA, USA: ADINA R\&D Incorporation; 2005.

532 [31] Aydın S, Yazıcı H, Baradan B. High temperature resistance of normal strength and autoclaved 533 high strength mortars incorporated polypropylene and steel fibres. Construction and Building 534 Materials 2008; 22:504-12. 
539 Table 1. Test matrix

540 Table 2. Results of tube compression test

541 Table 3. Summary of test results

542 Table 4. Confinement effects of GFRP tubes

543 Table 5. Mechanical properties of GFRP tubes used in simulation

544

545

546

547

548

549

550

551

552

553

554

555

556

557

558

559

560

561

562

563 
Fig. 1. Perforated FRP tube and concrete core.

566 Fig. 2. GFRP Tube configurations: ST tube, APT tube, DPT tube, ST-LW tube, APT-LW tube, and 567 DPT-LW tube.

568 Fig. 3. FTRC columns: (a) elevation and (b) cross-section (dimensions are in mm).

569 Fig. 4. Layout of GFRP tubes.

570 Fig. 5. GFRP tube reinforced concrete (FTRC) columns.

571 Fig. 6. Axial load-axial deformation behavior of GFRP tubes.

572 Fig. 7. Failure modes of GFRP tubes under axial compression.

573 Fig. 8. Locations of train gauges in GFRP tubes.

574 Fig. 9. Failure modes of FRTC columns.

575 Fig. 10. Axial load-axial deformation behavior of REF, ST, APT and DPT columns.

576 Fig. 11. Axial load- axial deformation behavior of REF, ST-LW, APT-LW and DPT-LW columns.

577 Fig. 12. Axial deformation-volumetric strain behavior of FTRC columns

578 Fig. 13. Constitutive model for concrete.

579 Fig. 14. Finite element model of FTRC column.

580

Fig. 15. Comparison between experimental results and simulation results.

581 Fig. 16. Effect of hole diameter (D) on the axial load-axial strain behavior of APT columns.

582 Fig. 17. Distribution of effective stress in perforated tubes: (a) hole diameter $=15 \mathrm{~mm}$, and (b) hole 583 diameter $=28 \mathrm{~mm}$.

Fig. 18. Effect of vertical hole spacing (S) on the axial load-axial strain behaviour of APT columns. 
585 Fig. 19. Distribution of effective stress in perforated tubes: (a) hole spacing $=25 \mathrm{~mm}$ and (b) hole 586 spacing $=75 \mathrm{~mm}$.

587

588

589

590

591

592

593

594

595

596

597

598

599

600

601

602

603

604

605

606

607

608

609

610

611 
613 Test matrix.

\begin{tabular}{|c|c|c|}
\hline Columns & Description & Reinforcement \\
\hline REF & Plain concrete columns & None \\
\hline ST & \multirow{6}{*}{$\begin{array}{l}\text { GFRP tube reinforced } \\
\text { concrete (FTRC) columns }\end{array}$} & Solid GFRP tube \\
\hline APT & & Axially perforated GFRP tube \\
\hline DPT & & Diagonally perforated GFRP tube \\
\hline ST-LW & & CFRP wrapped solid GFRP tube \\
\hline APT-LW & & CFRP wrapped axially perforated GFRP tube \\
\hline DPT-LW & & CFRP wrapped diagonally perforated GFRP tube \\
\hline
\end{tabular}

614

615

616

Table 2

Results of tube compression test.

\begin{tabular}{|l|c|c|c|c|c|c|}
\hline Tube types & ST & APT & DPT & ST-LW & APT-LW & DPT-LW \\
\hline Ultimate load $(\mathrm{kN})$ & 624 & 375 & 337 & 636 & 367 & 353 \\
\hline $\begin{array}{l}\text { Axial deformation at ultimate load } \\
(\mathrm{mm})\end{array}$ & 3.58 & 3.50 & 2.98 & 3.63 & 3.44 & 3.16 \\
\hline
\end{tabular}

618

619

620

621

622

623

624 
Table 3

627 Summary of test results.

\begin{tabular}{|c|c|c|c|c|c|}
\hline Specimen & $\begin{array}{l}\text { Yield load } \\
P_{y}(\mathrm{kN})\end{array}$ & $\begin{array}{c}\text { Axial } \\
\text { deformation } \\
\text { at yield load } \\
\delta_{y}(\mathrm{~mm})\end{array}$ & $\begin{array}{c}\text { Ultimate load } \\
\text { (fatal rupture of } \\
\text { FRP tube) } P_{u}(\mathrm{kN})\end{array}$ & $\begin{array}{l}\text { Axial deformation } \\
\text { at ultimate load } \\
\qquad \delta_{u}(\mathrm{~mm})\end{array}$ & $\begin{array}{c}\text { Ductility } \\
\mu\end{array}$ \\
\hline REF-1 & 613 & 1.18 & 613 & 1.18 & 1.00 \\
\hline REF-2 & 637 & 1.19 & 637 & 1.19 & 1.00 \\
\hline ST-1 & 680 & 1.59 & 975 & 10.34 & 6.50 \\
\hline ST-2 & 694 & 1.19 & 953 & 8.84 & 7.43 \\
\hline APT-1 & 674 & 1.32 & 653 & 5.27 & 4.00 \\
\hline APT-2 & 677 & 1.26 & 651 & 5.17 & 4.10 \\
\hline DPT-1 & 573 & 1.26 & 598 & 4.45 & 3.53 \\
\hline DPT-2 & 592 & 1.04 & 607 & 4.22 & 4.06 \\
\hline ST-LW-1 & 624 & 1.24 & 1011 & 13.33 & 10.75 \\
\hline APT-LW-1 & 588 & 1.15 & 679 & 4.64 & 4.03 \\
\hline APT-LW-2 & 634 & 1.29 & 648 & 4.54 & 3.52 \\
\hline DPT-LW-1 & 661 & 1.37 & 636 & 4.07 & 2.97 \\
\hline DPT-LW-2 & 602 & 1.23 & 589 & 3.65 & 2.97 \\
\hline
\end{tabular}

628

629

630

631

632

633

634 
Confinement effects of GFRP tubes.

\begin{tabular}{|c|c|c|c|c|}
\hline Columns & $\begin{array}{l}\text { Average ultimate load } \\
\qquad P_{c}(\mathrm{kN})\end{array}$ & $\begin{array}{l}\text { Ultimate load of GFRP } \\
\text { tube } P_{f}(\mathrm{kN})\end{array}$ & $\begin{array}{c}\text { Ultimate load of } \\
\text { unconfined concrete } \\
\text { core } P_{c 0}(\mathrm{kN})\end{array}$ & $\frac{P_{c}}{P_{c 0}+P_{f}}$ \\
\hline ST & 964 & 624 & \multirow{6}{*}{156} & 1.24 \\
\hline APT & 652 & 375 & & 1.23 \\
\hline DPT & 605 & 337 & & 1.23 \\
\hline ST-LW & 1011 & 636 & & 1.27 \\
\hline APT-LW & 664 & 367 & & 1.27 \\
\hline DPT-LW & 613 & 353 & & 1.20 \\
\hline
\end{tabular}

638 Note: $P_{c}=$ average ultimate load of the columns; $P_{f}=$ ultimate load of the GFRP tubes; $P_{c 0}=$ calculated

639 ultimate load of the concrete core without confinement, which is equal to the unconfined concrete

640 strength times the area of the concrete core; $\left(P_{c 0}+P_{f}\right)=$ calculated ultimate load of the columns

641 without confinement.

642

643 Table 5

644 Mechanical properties of GFRP tubes used in simulation.

\begin{tabular}{|c|c|c|c|c|c|c|}
\hline \multicolumn{2}{|c|}{$\begin{array}{l}\text { Ultimate Tensile Strength } \\
\qquad(\mathrm{MPa})\end{array}$} & \multicolumn{2}{|c|}{$\begin{array}{l}\text { Ultimate Compressive Strength } \\
\text { (MPa) }\end{array}$} & \multirow{2}{*}{$\begin{array}{l}\text { Shear Strength } \\
\text { (MPa) }\end{array}$} & \multicolumn{2}{|c|}{$\begin{array}{l}\text { Modulus of Elasticity } \\
\text { (GPa) }\end{array}$} \\
\hline Longitudinal & Transverse & Longitudinal & Transverse & & Longitudinal & Transverse \\
\hline 650 & 41 & 550 & 104 & 84 & 35.4 & 12.9 \\
\hline
\end{tabular}

645

646

647 


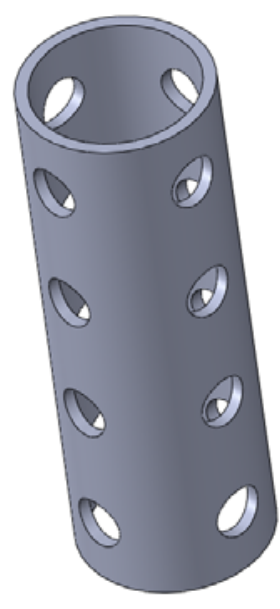

(a) Perforated FRP tube

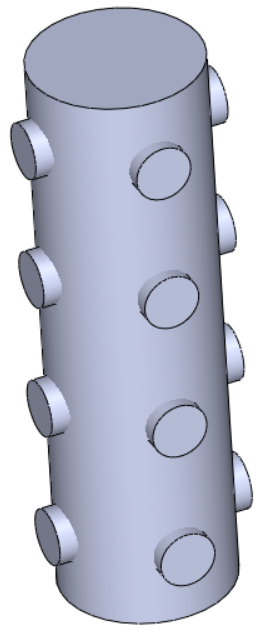

(b) concrete core

650

Fig. 1. Perforated FRP tube and concrete core.

651

652

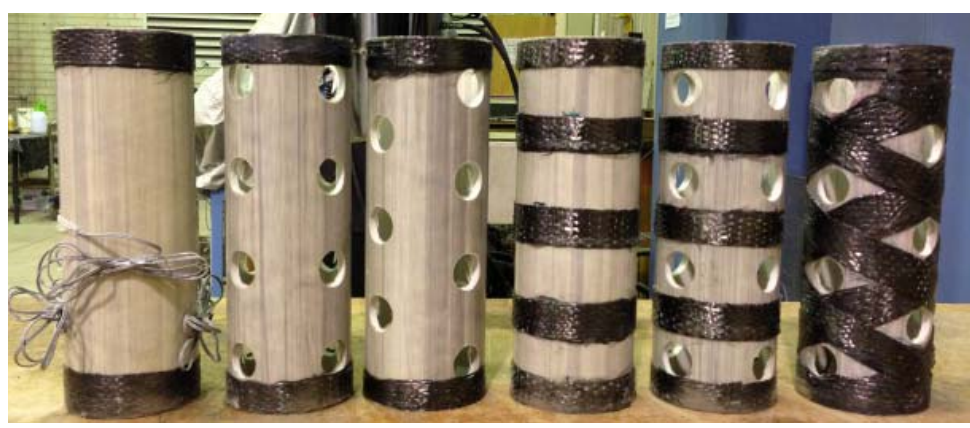

653 Fig. 2. GFRP Tube configurations: ST tube, APT tube, DPT tube, ST-LW tube, APT-LW tube, and 654 DPT-LW tube.

655

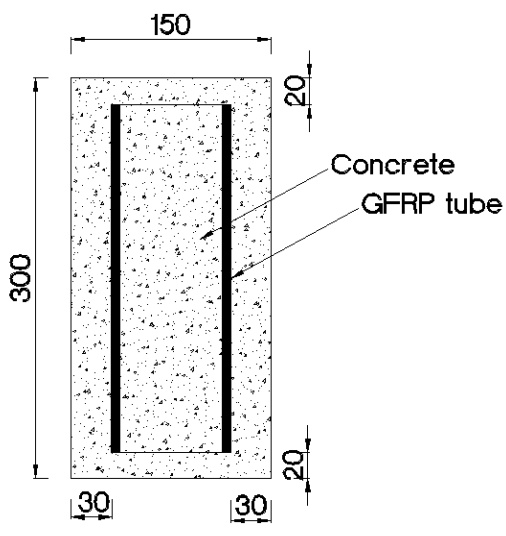

(a) elevation section

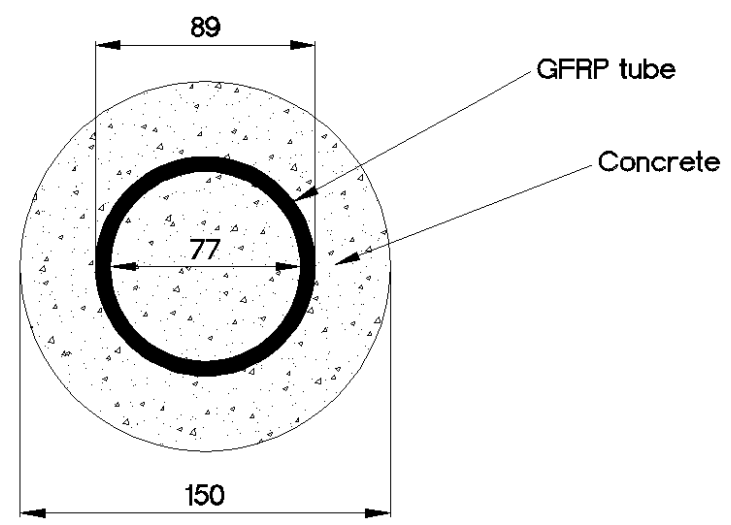

(b) cross-section

Fig. 3. FTRC columns: (a) elevation and (b) cross-section (dimensions are in mm). 
661

662

663

664

665

666

667

668

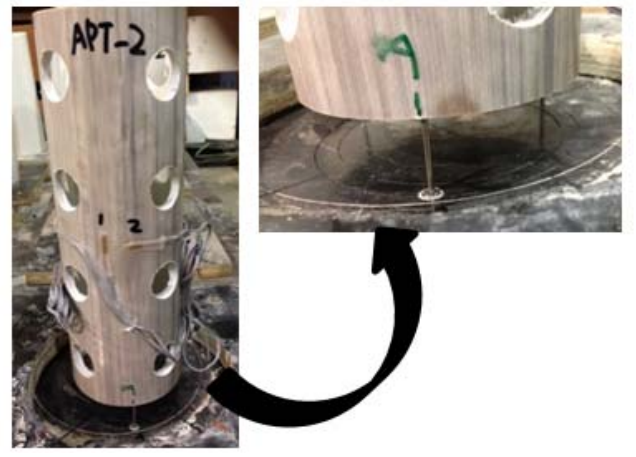

(a) $20 \mathrm{~mm}$ cover at bottom

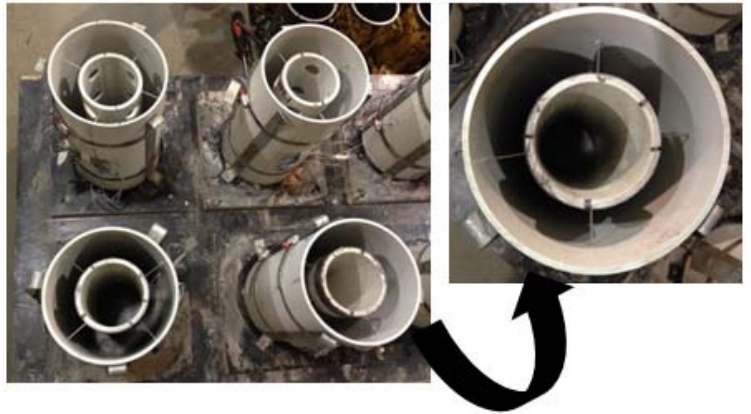

(b) $30 \mathrm{~mm}$ cover on the sides.

Fig. 4. Layout of GFRP tubes.

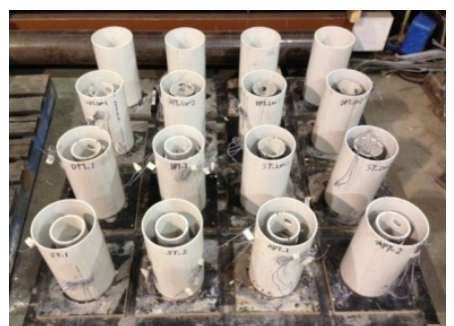

(a) before concrete casting

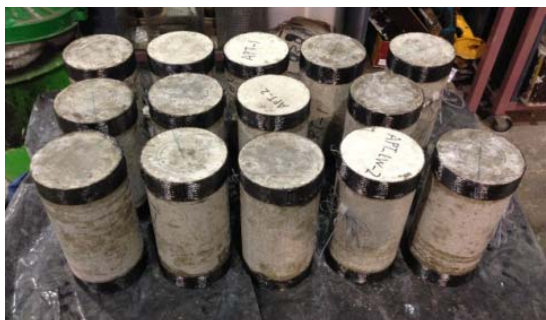

(b) after concrete casting.

Fig. 5. GFRP tube reinforced concrete (FTRC) columns.

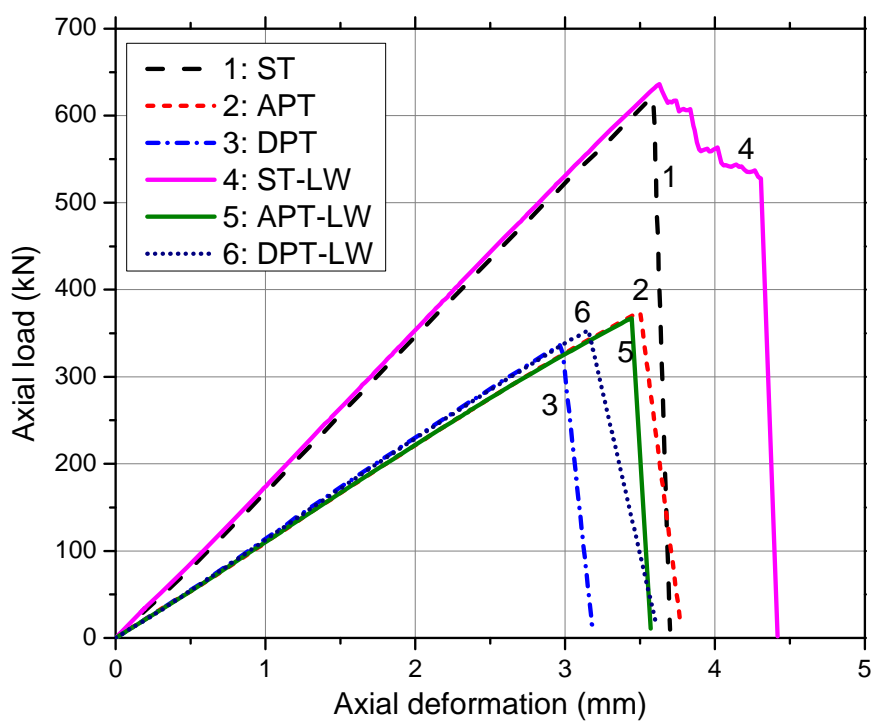

Fig. 6. Axial load-axial deformation behavior of GFRP tubes. 
673

674

675

676

677

678

679

680

681

682

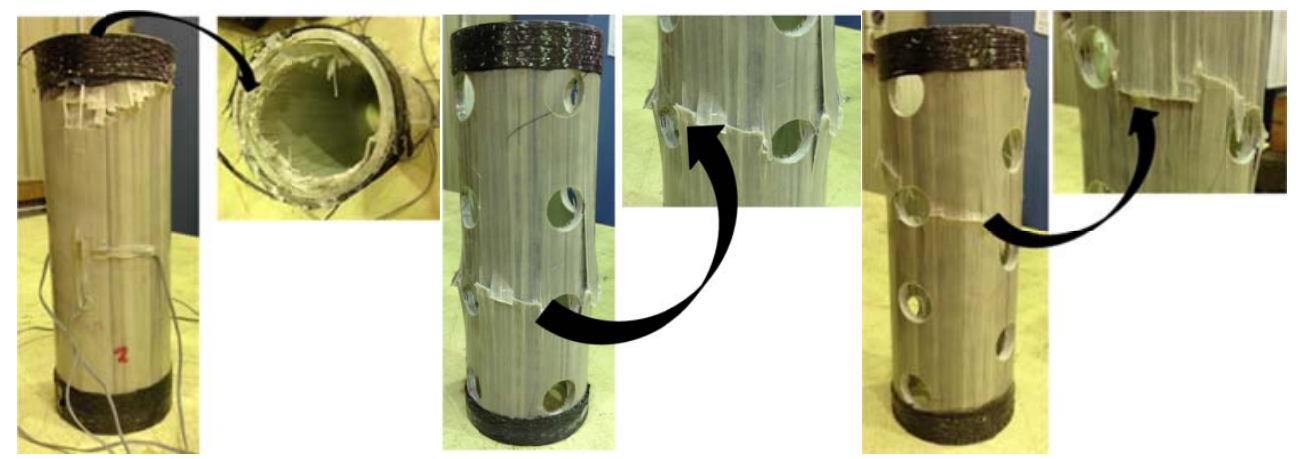

(a) ST tube

(b) APT tube

(c) DPT tube

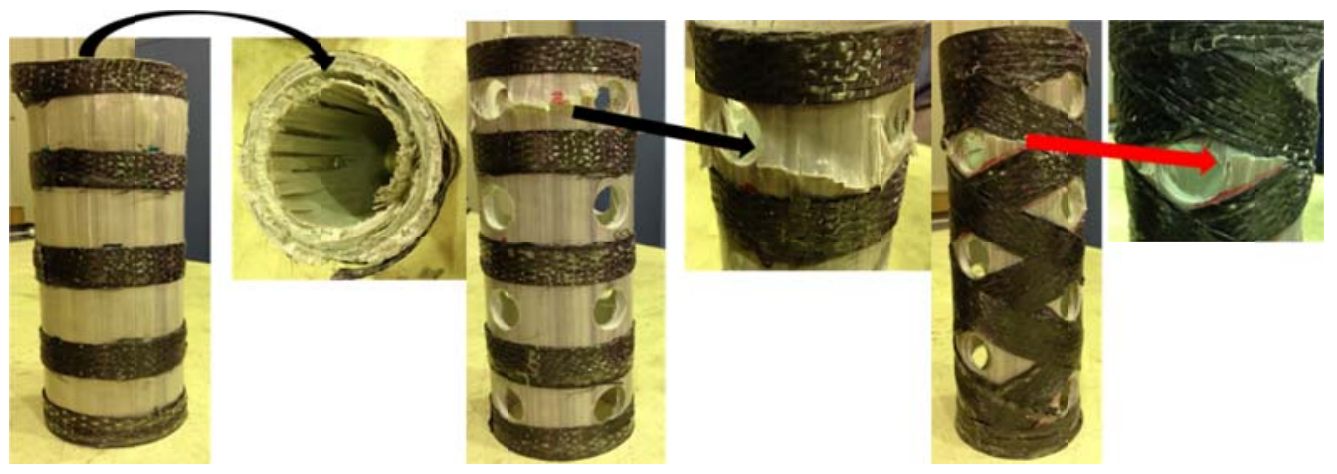

(d) ST-LW tube

(e) APT-LW tube

(f) DPT-LW tube

Fig. 7. Failure modes of GFRP tubes under axial compression.
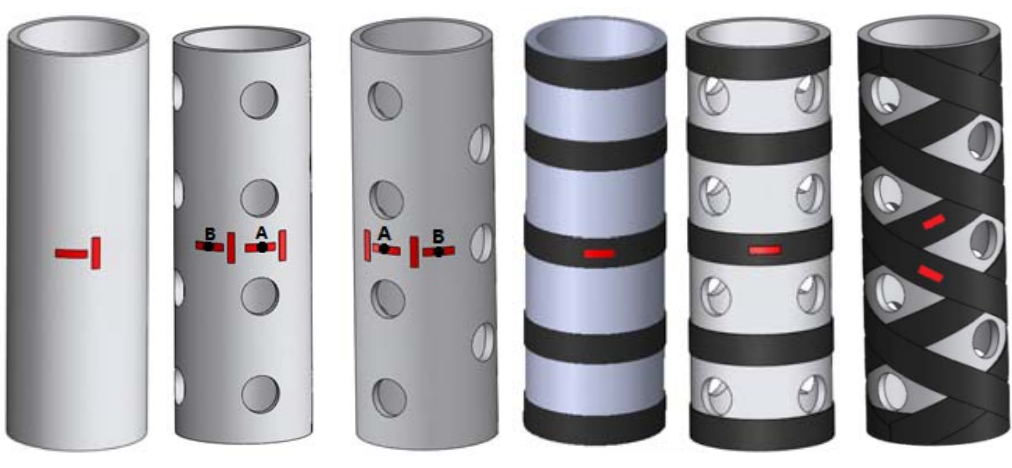

Fig. 8. Locations of train gauges in GFRP tubes. 
683

684

685

686

687

688

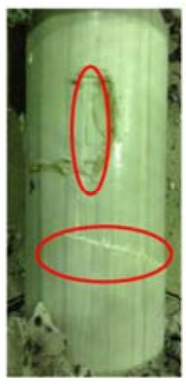

(a) ST

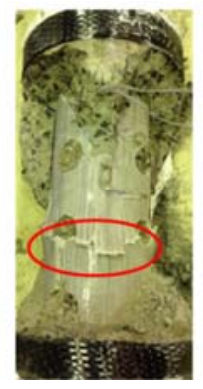

(b) APT

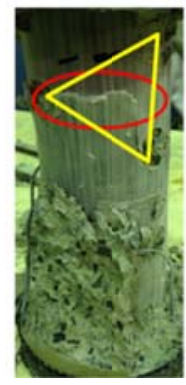

(c) DPT

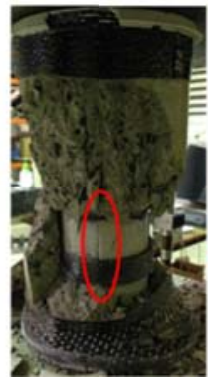

(d) ST-LW

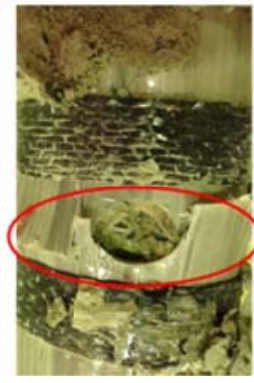

(e) APT-LW

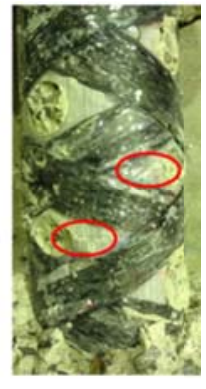

(f) DPT-LW

Fig. 9. Failure modes of FRTC columns.

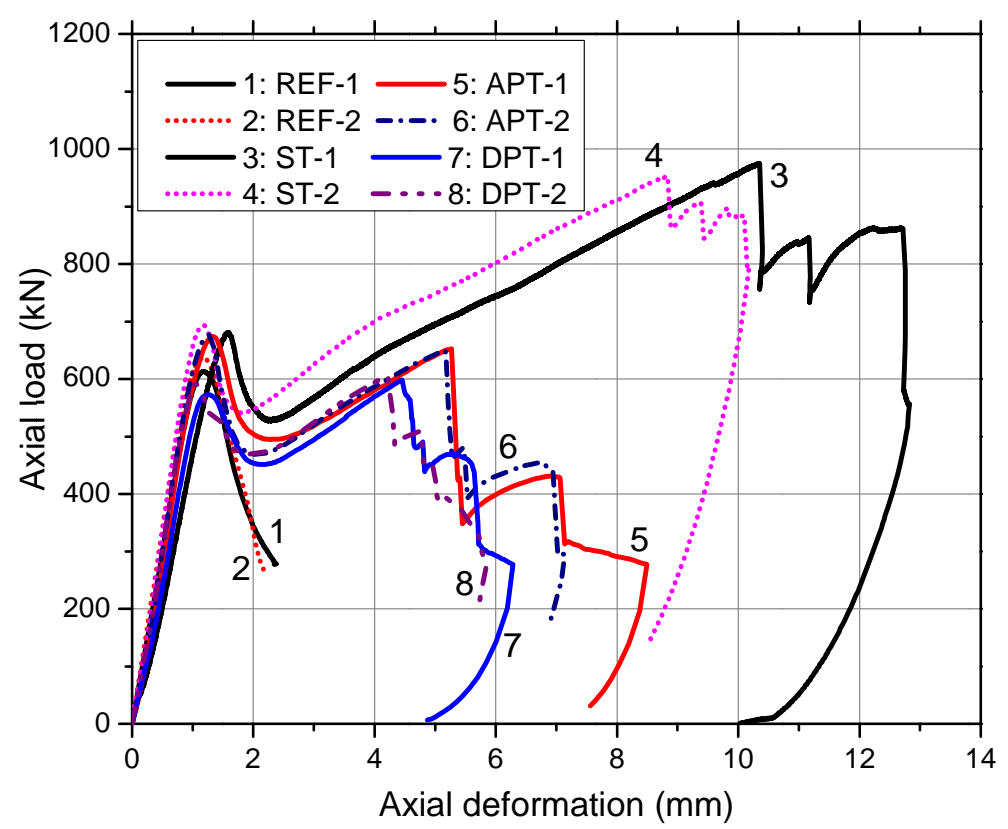

689

Fig. 10. Axial load-axial deformation behavior of REF, ST, APT and DPT columns.

691 


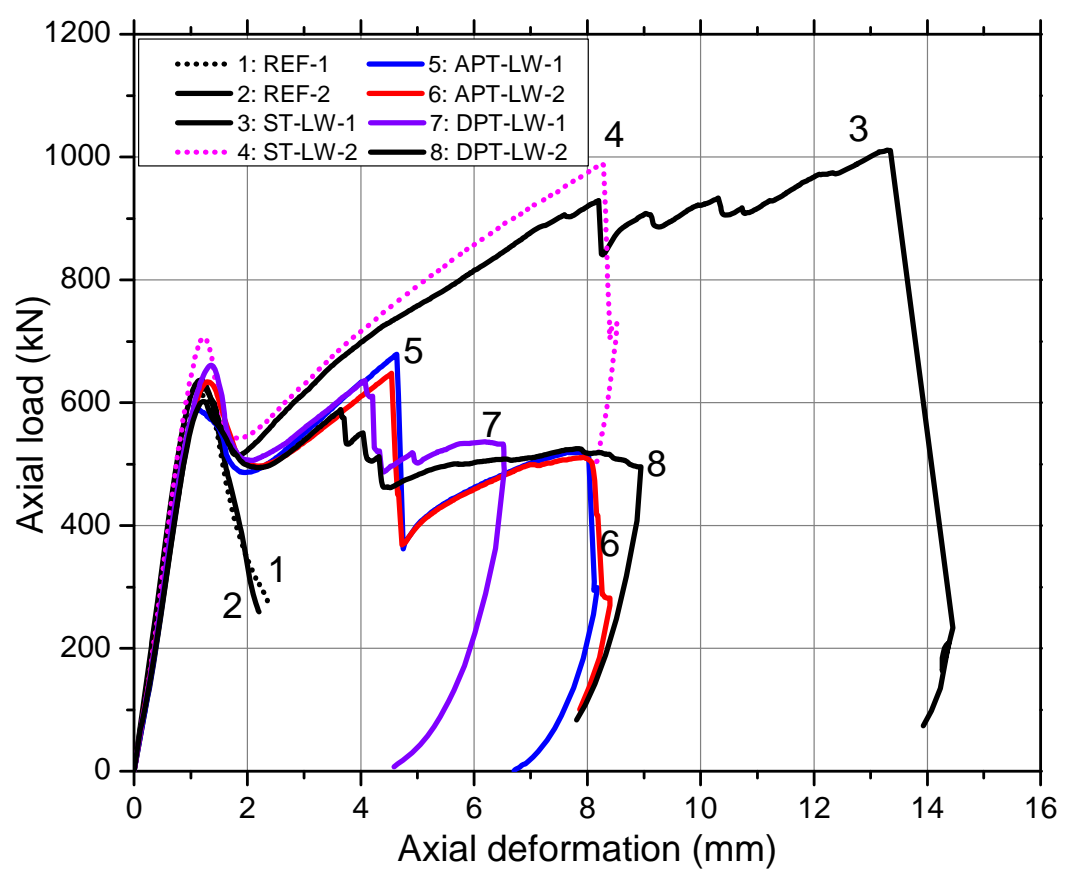

Fig. 11. Axial load- axial deformation behavior of REF, ST-LW, APT-LW and DPT-LW columns.

695

696

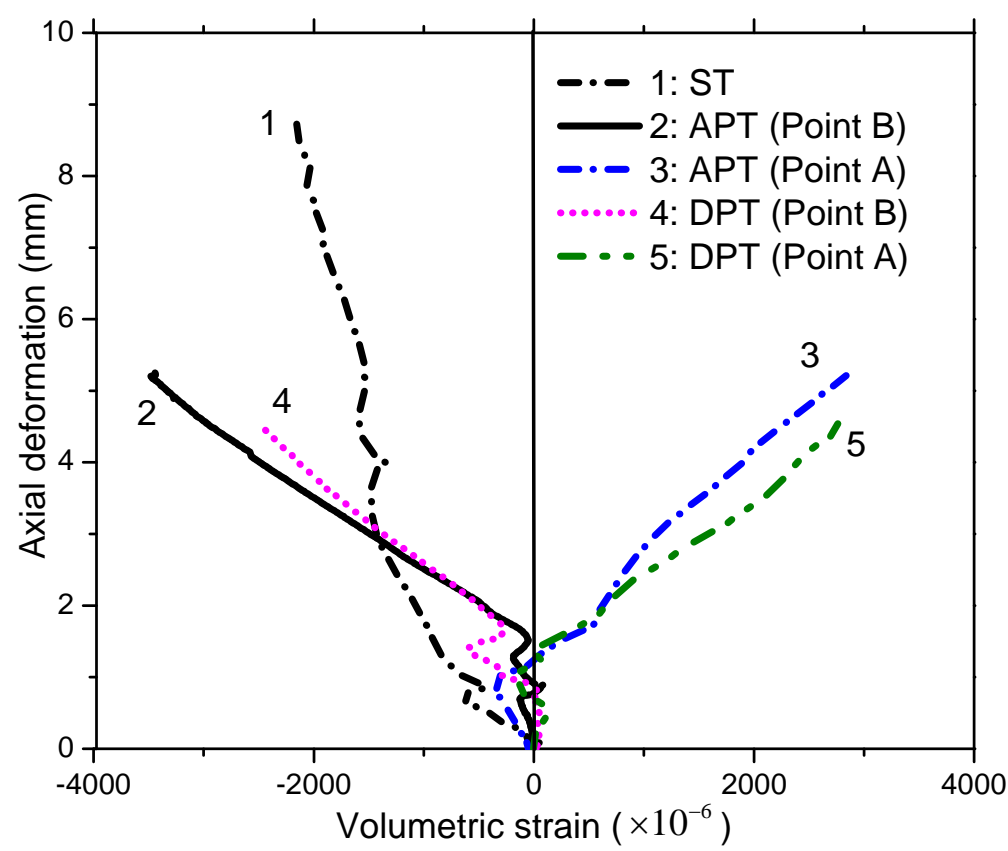

Fig. 12. Axial deformation-volumetric strain behavior of FTRC columns. 
700
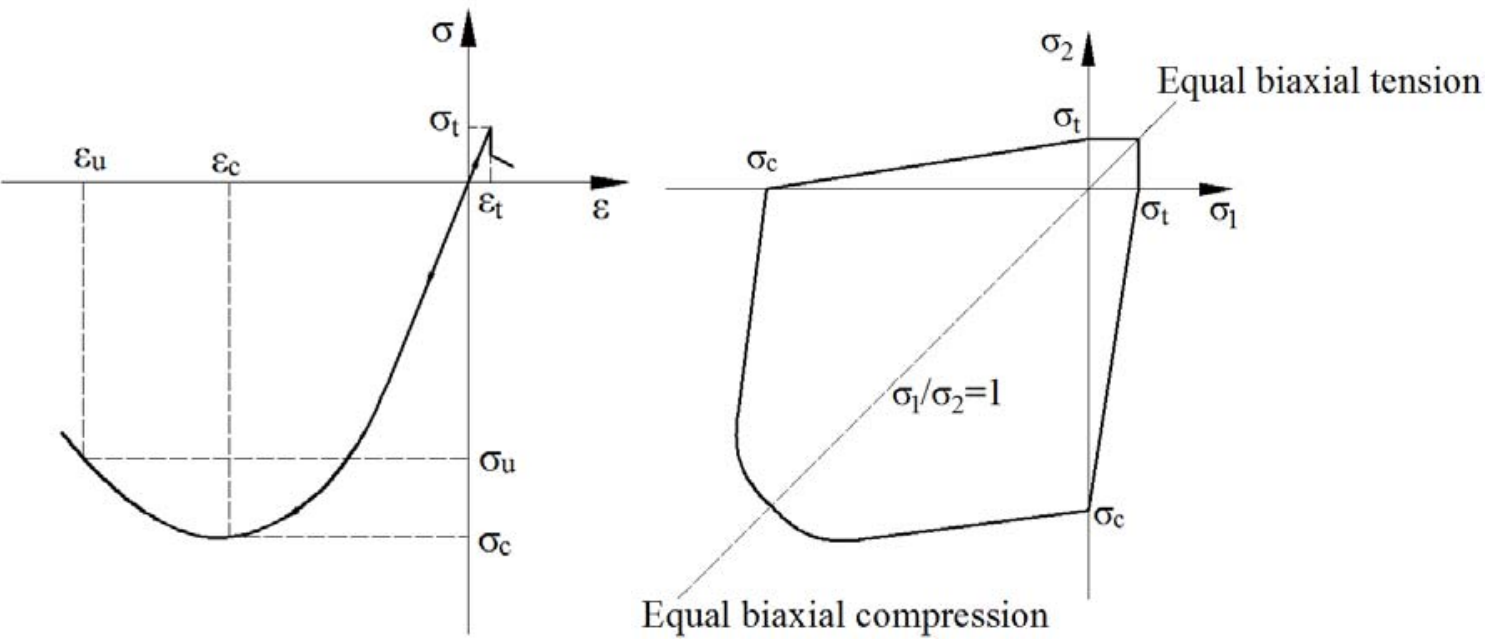

(a) Typical uniaxial stress-strain curve for concrete

(b) Biaxial failure envelope for concrete
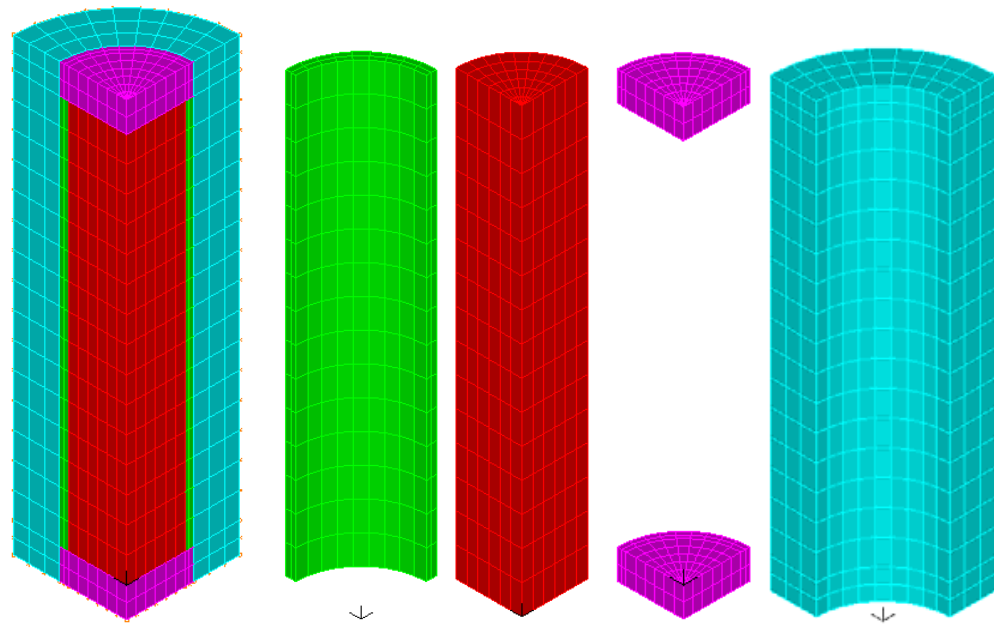

705

Fig. 14. Finite element model of FTRC column. 


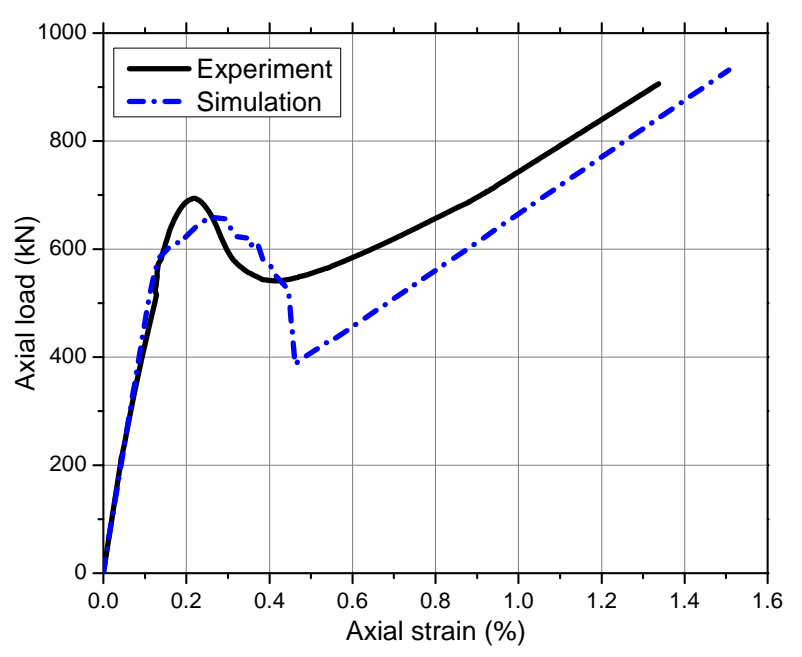

(a) ST column

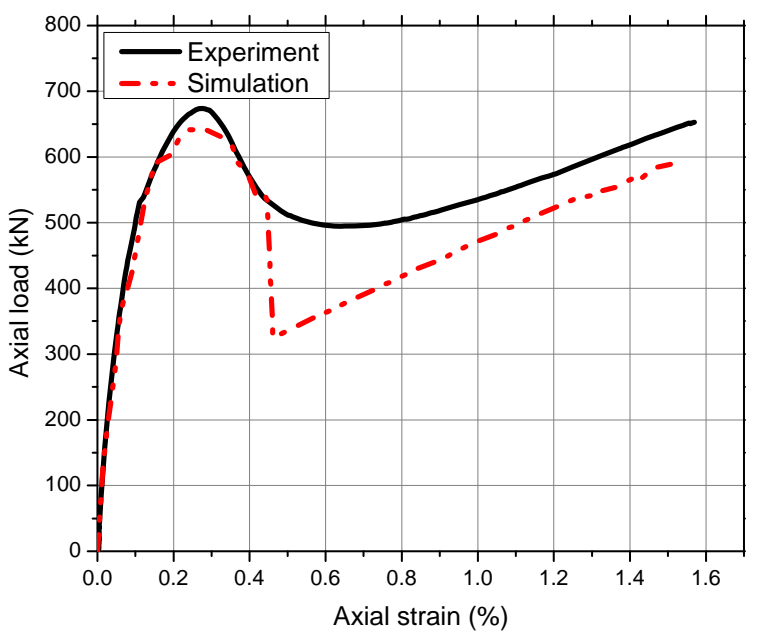

(b) APT column

Fig. 15. Comparison between experimental results and simulation results.

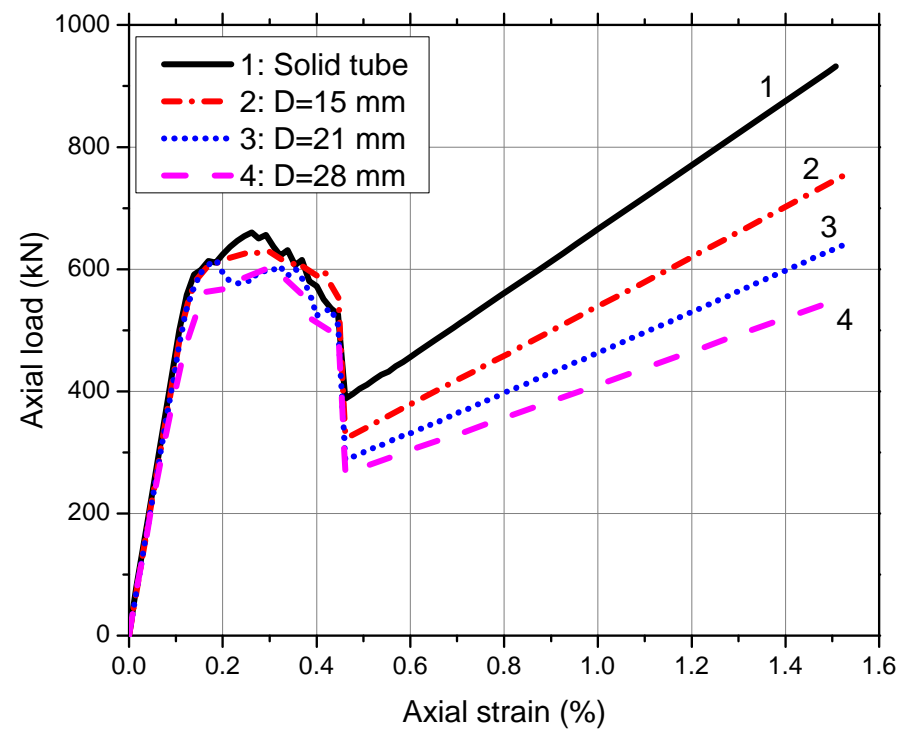


715

716

717

718

719

720

721

722

723

724

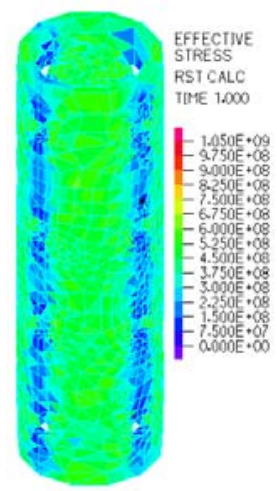

(a) hole diameter=15 $\mathrm{mm}$

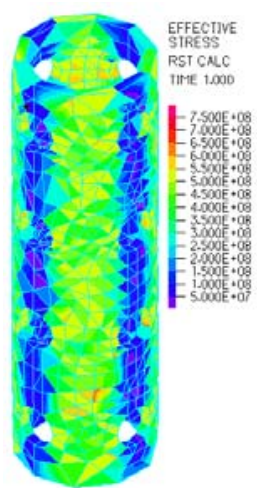

(b) hole diameter $=28 \mathrm{~mm}$

Fig. 17. Distribution of effective stress in perforated tubes: (a) hole diameter $=15 \mathrm{~mm}$, and (b) hole diameter $=28 \mathrm{~mm}$.

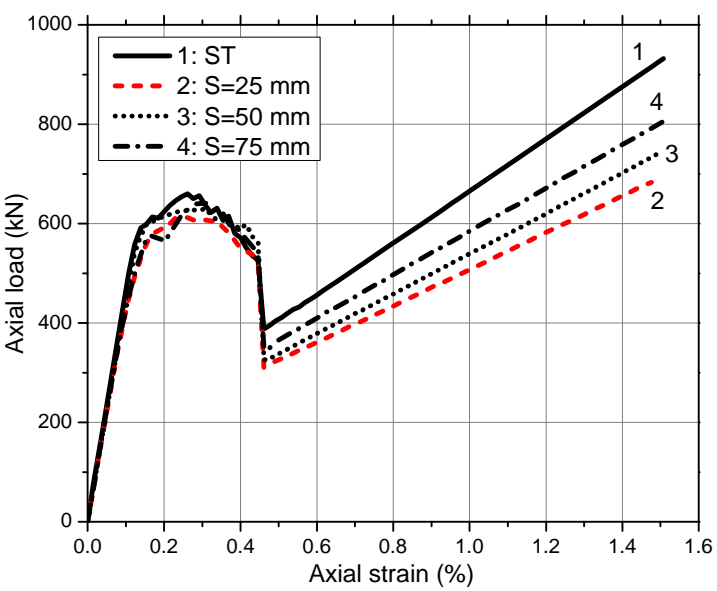

Fig. 18. Effect of vertical hole spacing (S) on the axial load-axial strain behaviour of APT columns. 


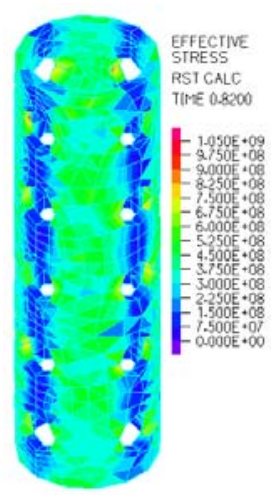

(a) hole spacing=25 mm

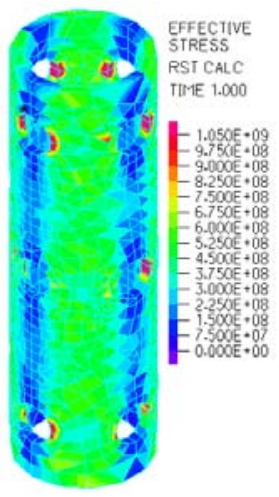

(b) hole spacing $=75 \mathrm{~mm}$
727
Fig. 19. Distribution of effective stress in perforated tubes: (a) hole spacing $=25 \mathrm{~mm}$ and (b) hole spacing $=75 \mathrm{~mm}$. 